\title{
A sala de aula na educação de jovens e adultos
}

\section{Classroom in youth and adult education}

\author{
Veronica Branco*
}

\begin{abstract}
RESUMO
Este artigo apresenta as relações estabelecidas pela autora entre os resultados da pesquisa realizada junto a professores alfabetizadores de crianças e jovens e adultos e as observações que desenvolveu com os estagiários da disciplina de Prática de Ensino de Magistério do Curso de Pedagogia da UFPR, em escolas da comunidade de Curitiba. Relata depoimentos de alunos da EJA como demonstrativo da realidade de sala de aula, comenta referenciais teóricos lingüísticos, psicolingüísticos e pedagógicos sobre a alfabetização e sugere encaminhamento para a melhoria da formação dos professores alfabetizadores.

Palavras-chave: formação de professor; alfabetização; aprendizagem da leitura e da escrita.
\end{abstract}

\begin{abstract}
This article presents its author's established relations between the results of research in literacy among teachers of children and teenagers and also adults and her observations developed in schools of Curitiba's community with trainees from the discipline of Teaching Practice for Elementary School in Pedagogy Course of UFPR. This article presents reports from EJA (Adult and Teenagers Education) students as a demonstrative of classroom reality, as well as theoretical analyses references from linguistics, psycholinguistics

* Mestre em Educação: Recursos Humanos e Educação Permanente. Professoraadjunta do Depto. de Teoria e Prática de Ensino do Setor de Educação da Universidade Federal do Paraná. Professora das disciplinas de Prática de Ensino de Magistério e Alfabetização no Curso de Pedagogia.
\end{abstract}


and pedagogy about literacy. This article also suggests a literacy teachers improvement.

Key-words: teaching training; literacy; writing and reading learning.

\section{Introdução}

Este artigo apresenta as relações estabelecidas entre os resultados de pesquisa realizada pela autora em parceria com uma colega e alunos bolsistas de Iniciação Científica da Universidade Federal do Paraná - UFPR, do Programa LICENCIAR, sobre as práticas educativas de professoras alfabetizadoras de crianças e de Jovens e Adultos (EJA) Branco,V., Haracemiv, S.M.C. e outros (2004), e as reflexões sobre sua experiência como professora da disciplina de Prática de Ensino no Curso de Pedagogia da UFPR. Nesta condição, acompanhando seus alunos-estagiários, assistiu nas escolas da comunidade a aulas de alfabetização, ministradas por professores da rede estadual de ensino, da rede municipal de Curitiba, de instituições sociais - Sesc - e de estagiários. Além disso, ao longo de sua carreira docente, privilegiou os estudos e pesquisas sobre a leitura e a escrita, e é sob essas óticas que tece suas reflexões.

No contexto da pesquisa realizada em escola da periferia da cidade, em bairro com muitos migrantes do interior do estado e de estados vizinhos, os alunos que encontramos nas salas de aula da EJA eram em maioria mulheres, na faixa etária de 22 a 68 anos. A jovem de 22 anos apresentava quadro de deficiência mental. Todas elas pertenceram, quando crianças, a comunidades rurais desprovidas de escolas nas proximidades, o que deu margem ao preconceito paterno de que “... mulher não precisa estudá, senão vai se perdê" ( $\mathrm{sic}$ ) para não deixá-las freqüentarem a escola distante. No entanto, afirmaram que seus irmãos estudaram. Já adultas, sentiram-se mais inferiorizadas ainda por não saberem ler e escrever, o que as relegou a uma vida doméstica de quase reclusas. A vergonha pelo desconhecimento das habilidades básicas de leitura e escrita e a vontade de ajudar seus filhos nos deveres escolares e de melhorarem no conceito deles eram as razões de estarem freqüentando as classes da EJA. Algumas, poucas, que trabalhavam como empregadas domésticas, mencionaram a possibilidade de arranjarem um emprego com salários melhores porque reconheciam que o 
não domínio da leitura e da escrita lhes impedia de, conforme afirmaram: “... procurar emprego em casa fina que paga mais, mais lá tem produto que a gente não conhece, tem que lê prá não se atrapalhá, ... a patroa sai, deixa bilhete, receita, manda fazê compra, e aí não dá né...” (sic).

Os poucos homens que encontramos nas salas da EJA haviam freqüentado escolas, se evadido sem aprender a ler e escrever e tinham como forma de subsistência subempregos como: faxineiros, carregadores, catadores de material reciclável, vendedores de frutas em esquinas da cidade. Afirmaram que buscaram as salas da EJA porque sentiam que eram enganados e explorados em suas relações de trabalho e comerciais. Além disso, queriam se livrar das situações ridículas em que se colocaram por não saberem ler e escrever. Exemplo disso foi a narrativa de um aluno sobre a situação em que precisou utilizar um sanitário em um restaurante de beira de estrada. As portas estavam identificadas por letras que ele desconhecia. Contou que esperou para ver onde as pessoas entravam para descobrir qual era o sanitário masculino. Como o movimento era pouco, e havia poucas pessoas no restaurante, ele teve que aguardar algum tempo até que observou um trabalhador da limpeza entrar em uma das portas. Julgou que aquele fosse o sanitário masculino e já muito precisado entrou rapidamente na mesma porta. Ao sair do reservado do sanitário, deu de cara com duas mulheres que se puseram a gritar, chamando-o de tarado. A explicação para o fato é que o trabalhador da limpeza, aproveitando a ausência de mulheres no restaurante, entrou no sanitário feminino para fazer um pequeno reparo na torneira e se retirou de lá rapidamente. Nosso personagem, no entanto, demorou mais e foi flagrado pelas mulheres no local proibido para ele. Finalizou dizendo: "a senhora imagina a vergonha que eu passei prá dizer que não sabia ler". A vergonha maior não era por ter entrado no local errado e sim por ter que se justificar dizendo ser analfabeto.

Todos os alunos que encontramos conheciam moedas e notas e utilizavam o dinheiro em pequenas transações: pagar o ônibus e comprar alguns produtos na venda próxima de suas residências. No entanto, fazer compras em supermercados, que cada vez mais substituem o pequeno comércio dos bairros, trouxe novos problemas e limitações para os nossos sujeitos.

Como se pode ver, as experiências e motivos para procurarem as Escolas de Jovens e Adultos são diferenciados para os gêneros.

Em outras turmas de EJA, fora da pesquisa, os dados sobre os sujeitos apresentaram pouca variação. A exceção ficou por conta das turmas do SESC, diurnas, que reúnem grande número de jovens do sexo feminino 
que freqüentaram escola quando crianças e não aprenderam a ler e escrever. Nesse contexto também encontramos a figura do pai preconceituoso que dificultou a escolarização das mulheres. Muitas afirmaram que seus pais as impediram de freqüentar a escola diante do insucesso inicial apresentado por elas, acrescentando o dizer de seus pais: “... filha mulher que não tem cabeça pro estudo, é melhor ficá ajudando em casa, pra não perdê tempo na escola" (sic).

Nas classes de EJA da rede pública que conhecemos, todas funcionando no horário noturno, atuavam professores das séries iniciais regulares. Na pesquisa buscamos professores que atuassem simultaneamente nas turmas de alfabetização de crianças e de adultos, o que não foi freqüente e fez com nossa pesquisa se transformasse em um estudo de caso. Indagando sobre o fato, constatamos que os professores acham que é muito pesado, cansativo, trabalhar com duas turmas de alfabetização; por isso preferem trocar de série quando assumem as classes de EJA no período noturno.

A maioria é mulher, com alguma experiência, têm em média mais de cinco anos de trabalho. Todas têm curso de Magistério de segundo grau, algumas têm licenciaturas variadas como: Pedagogia, História, Letras, Geografia e até curso de especialização.

Já nas salas do SESC encontramos atuando alguns professores das séries iniciais do Ensino Fundamental da rede pública municipal e muitos estudantes universitários dos cursos de licenciaturas, sem curso de magistério de segundo grau e com pouca ou nenhuma experiência de sala de aula.

Independente da instituição em que atuem e da formação que tenham os professores, as práticas pedagógicas de alfabetização estão marcadas pelo referencial estruturalista/behaviorista representado pelo uso dos métodos silábicos.

\section{Uma retrospectiva sobre os referenciais da alfabetização}

As classes de alfabetização da EJA surgem no Brasil no período em que só se dispunha do referencial teórico sobre métodos de ensino. Essa é também a característica mundial da alfabetização durante os primeiros setenta anos do século XX. São métodos organizados no âmbito da concepção estruturalista (behaviorista) da linguagem. Nesse referencial, ler era 
adquirir a competência técnica para decodificar o código da língua escrita e escrever era codificar a língua escrita. Ler e escrever eram processos técnicos, correlatos e inversos.

A teoria da comunicação vigente e que também dá suporte a essa visão da linguagem destacava o papel do emissor como um codificador e o papel do receptor como o de um decodificador, sem grande preocupação com o conteúdo veiculado.

Essa concepção um tanto simplista das habilidades de leitura escrita é correlata aos estudos lingüísticos de Saussure e posteriormente de Chomsky, conforme citado por Lyons:

todas as línguas naturais são, seja na forma falada, seja na forma escrita, linguagens, no sentido de sua definição: uma vez que (a) toda língua natural possui um número finito de sons (e um número finito de letras em seu alfabeto - considerando que tenha um sistema alfabético para a escrita); e (b) embora possa haver um número infinito de sentenças distintas na língua, cada sentença pode ser representada como uma seqüência finita desses sons (ou letras) (LYONS, 1987, p. 20).

O que se depreende da citação, onde o termo língua é empregado no plural para veicular o significado de idioma, é que não existe uma língua ou código desligado da linguagem, que são as formas da língua em uso pelos seus usuários, com suas diferentes expressões e intenções. Porém, é essa distinção que está na raiz da concepção dos métodos de alfabetização. Se o sistema de uma língua é composto por um número finito de sons ou letras, basta ensinar esses sons e letras para que o indivíduo aprenda a ler e escrever, uma vez que ele já domina essa língua na sua forma natural.

Em nosso país, os métodos de alfabetização mais utilizados foram os métodos sintéticos, os que partem das unidades menores para as maiores. E os mais divulgados eram os que empregavam a silabação. Nesse contexto, o Método Paulo Freire é inovador ao introduzir, em meados do século XX, uma concepção ainda estruturalista, porém de marcha analítica, privilegiando o sentido da linguagem e não apenas da língua considerada como código e empregando como ponto de partida a unidade de significado: a palavra geradora. No entanto, ao ser utilizado de forma generalizada, muitas vezes por professores leigos, perdeu sua grande riqueza, que era a exploração do universo lingüístico dos aprendizes, para tão-somente pas- 
sarem a reproduzir as palavras pesquisadas pelo autor, meramente como referência para os exercícios de composição e decomposição de palavras. Isso fez com que o método funcionasse efetivamente como um método silábico, porque passou a aplicar indistintamente as palavras originais, caso da palavra TIJOLO, de onde se retiraram as famílias silábicas do TA, TÉ, TI, TO, TU, do JÁ, JE, JI, JO, JU e do LÁ, LÉ, LI, LO, LU, para a composição de novas palavras, independente das condições do aprendiz e da visão do mundo do trabalho que o aluno tivesse como referência.

A partir do final dos anos 70 do século XX, por influência dos estudos da Psicologia Cognitiva e da difusão da Psicologia Construtivista, ocorre uma ruptura nos referenciais teóricos da alfabetização, em todo o mundo, que deixam de enfocar o ensino - que é o contexto dos métodos - para voltar-se para a aprendizagem. A partir dessa época, as habilidades de leitura e de escrita passam a ser vistas como habilidades cognitivas complexas e específicas.

O trabalho de pesquisa de Emília Ferreiro sobre a Psicogênese da Língua Escrita (1985, p. 15-38) é o principal demarcador desse novo enfoque teórico. É a descoberta que, por trás da mão que escreve e dos olhos e ouvidos que captam os sinais e sons da língua, existe um sujeito que pensa sobre esse objeto social que é a linguagem escrita. Portanto, não basta que se queira ensinar determinado conteúdo e se disponha de bons métodos de ensino: é preciso ajustar o objeto de conhecimento, isto é, as formas como esse "objeto linguagem" é apresentado às condições de quem aprende.

Também por essa época, final dos anos 70, aportam na academia os referenciais teóricos sociointeracionistas que introduzem Vygotsky e sua visão diferenciada sobre o papel do professor no ensino: ele deixa de ser apenas um transmissor/informador para ser um mediador do conhecimento.

Nesses mesmos quadro e época, a alfabetização se torna objeto de estudo dos lingüistas, que procuram demonstrar que aprender a ler e escrever é empregar essas habilidades nas relações sociais em que se interage e, principalmente, que não se aprende o código fora das situações de uso da linguagem, como mostravam os textos empobrecidos das cartilhas de alfabetização.

No entanto, o que se observa ainda hoje é que o velho método silábico do "Ivo viu a uva" foi modenizado para incluir um texto mais longo, como: "Vovó Viviane vive na favela. De dia ela lava roupa e de noite vê novela na TV", porém o referencial estruturalista continua servindo de referência aos professores alfabetizadores. O modelo teórico se mantém, as palavras foram reunidas para explorar o som e a grafia da letra "V". Continua sendo 
um texto especialmente organizado para os alfabetizandos, um texto impossível de ser encontrado e produzido em situação natural de uso da linguagem. E, no entanto, são os textos reais, os naturais, na forma como circulam, que informam ao aprendiz como é a língua que se escreve. Muito antes de aprender o como se escreve, o aprendiz precisa saber o que é que se escreve.

\section{Sobre as práticas alfabetizadoras}

$\mathrm{Na}$ busca das práticas alfabetizadoras encontramos situações distintas.

A primeira delas, no estudo de caso que realizamos, a professora empregava com as crianças e com os adultos o mesmo procedimento. As turmas se encontravam em diferentes etapas do método de alfabetização, devido à "maior dificuldade dos adultos para aprender", argumento utilizado pela professora para justificar que, no mesmo dia, no período da manhã ela estivesse trabalhando com palavras com a letra " $G$ " e de noite, na sala da EJA, estivesse trabalhando com a letra "B", parecendo entender que as duas turmas deveriam apresentar o mesmo andamento de aprendizagem.

A professora organizou seu dia de trabalho destinando o horário inicial para as atividades de escrita e o horário após o intervalo do recreio para as atividades de leitura.

Para a realização das atividades de escrita:

O texto trabalhado com as crianças apresentava a Girafa Girafina:

"Girafa Girafina foi passear no zoológico.

Tomou guaraná gelado e ficou com dor de garganta.

A mãe dela colocou uma blusa de gola para proteger a garganta da Girafina e tratou-a com coisas gostosas: gelatina, geléia de goiaba e canja de galinha."

Na turma da EJA o texto empregado apresentava o Papai Boi da Cara Preta:

"Papai Boi da Cara Preta queria levar seus filhinhos Bilu e Bulu para passear no balão".

Em uma comparação sucinta entre os dois textos, poder-se-ia dizer, sem maiores análises, que o texto dado para as crianças era maior e mais 
informativo que o dado para os adultos, porém as crianças estavam mais adiantadas que os alunos da EJA. Possivelmente elas teriam passado pelo mesmo texto quando estudaram a letra "B". Deixamos de apresentar a análise realizada no contexto da pesquisa por não ser o objeto deste texto. Porém, constatamos que a forma de trabalhar com os textos foi a mesma, para os dois grupos de alunos, na seguinte seqüência:

- Escrita prévia do texto, no quadro-negro, pelo professor (antes dos alunos entrarem na sala). Para as crianças, foram utilizadas letras no tipo caixa-alta e para os adultos, letras no tipo cursiva.

- Comentário sobre o texto e a letra do alfabeto a ser estudada naquele dia.

- Leitura coletiva do texto.

- Retirada, do texto, das palavras iniciadas pela letra em estudo e escritas no quadro-negro sob a forma de coluna.

- Cópia integral do texto pelos alunos.

- Desenho da situação apresentada no texto.

Para a realização das atividades de leitura:

A professora mostrou um livro de história infantil: A centopeinha. Um texto que apresentava a situação de uma centopéia-criança que foi comprar sapatos com sua mãe.

Pediu para as crianças ficarem nos seus lugares para que todos pudessem ouvir a história e iniciou a leitura com o livro voltado para si, parando após a leitura de cada página para mostrar a respectiva ilustração. Ao final, repassou as páginas mostrando e comentando as imagens para os alunos.

Terminada a leitura, fez algumas perguntas sobre o texto, à guisa de interpretação, e comentou o inusitado da quantidade de sapatos que seria necessário comprar. Riu com as crianças e encerrou as atividades.

$\mathrm{Na}$ turma da EJA a professora fez exatamente a mesma leitura, a da Centopeinha.

Indagamos à professora por que empregava diferentes tipos de letras para escrever no quadro negro. A resposta foi que os adultos não aceitam ser ensinados com a letra tipo caixa-alta, porque acham que isso é coisa de criança.

Indagamos então por que ela empregava a letra tipo caixa alta com as crianças. A resposta foi de que era determinação do Currículo da Prefeitura. 
Parafraseando o personagem de Guimarães Rosa: "obedecer é mais fácil que entender” (GUIMARÃES ROSA, 1986, p. 287). A professora não sabe por que deve empregar a letra tipo caixa alta com as crianças, mas o faz, de forma obediente.

A segunda situação que encontramos ocorreu nas classes de EJA, em que os alunos de Pedagogia realizavam estágio:

Não encontramos uma atividade planejada, qualquer que fosse ela. Em algumas delas, os alunos tinham uma apostila e a professora se limitava a trabalhar com o texto e as atividades previstas na seqüência. Em outras classes, a professora escolhia um tema do currículo, conversava com os alunos, dava explicações e passava exercícios no quadro. Invariavelmente se fazia uma atividade de cópia que tomava a maior parte do tempo da aula. Nunca presenciamos o professor fazendo leituras de texto para os alunos.

Dentro desse esquema é que as professoras desejavam que seus estagiários, meus alunos do terceiro ano de Pedagogia, preparassem as atividades para os alunos da EJA.

Assim, uma aluna que deveria realizar a regência de classe preparou uma aula para trabalhar com os alunos sobre a importância do lixo reciclável e seu aproveitamento. Comparecemos à escola, sentamos em cadeiras, no fundo da classe, para acompanhar o desempenho da estagiária. A turma era composta por vinte alunos, a maioria mulheres, porém com considerável presença masculina, sete ao todo.

A estagiária pediu que os alunos formassem um semicírculo com as carteiras que se encontravam enfileiradas. Após algum barulho, que desagradou a professora regente, a ponto de intervir pedindo silêncio, a estagiária ligou o retroprojetor, onde se encontrava uma transparência, copiada da página de um livro didático, com letras muito pequenas. Apagou a luz e anunciou solenemente: "Momento conceitual". Passou então a ler o texto de forma linear. Ao fim de alguns segundos, os alunos demonstraram inquietação e começaram a conversar. A professora regente pediu silêncio algumas vezes e finalmente, quando a balbúrdia na sala já era grande e a estagiária continuava lendo o texto da transparência, a professora regente acendeu a luz e, muito nervosa, fez um sermão para os alunos. Diante da situação, eu e minha colega sugerimos aproveitar a disposição das carteiras em semicírculo, em que todos se encontravam, para que os alunos falassem sobre suas vivências e conhecimentos de como era o meio ambiente no bairro, para não fugir do tema proposto para a aula. A estagiária e a professora regente concordaram. Pedimos então que, primeiramente, os alunos falassem sobre as razões que os levaram a procurar a EJA. Os 
alunos passaram a falar com interesse sobre suas razões para buscar a EJA, bem como das situações negativas que já tinham enfrentado por não saber ler. A ocorrência do sanitário, já descrita, apareceu nesse contexto. Ao final, os alunos abordaram o lixo reciclável e a importância de separá-lo. Não houve naquela noite tempo para a realização de atividades escritas com os alunos, seja no quadro-negro ou nos cadernos. Razão porque a professora regente sentiu que a intervenção das professoras da universidade tinha atrapalhado, deliberadamente, a aula da estagiária.

Pelos depoimentos dos alunos e informação da professora regente, soubemos que treze deles ainda não identificavam todas as letras do alfabeto. Qual então a importância da realização da atividade escrita naquele momento? O registro mecânico da atividade, em cumprimento de um ritual escolar? A professora regente e a estagiária não compreenderam a riqueza dos depoimentos porque eles não se apresentaram conforme o contido no livro didático. Não conseguiram enxergar que essa atividade oral poderia ser retomada em outra aula para gerar muitos textos coletivos.

\section{O que revela esse quadro?}

Entre outras coisas que:

1946 ,

- alfabetizar nesse início de século XXI ainda é uma tarefa que acontece ao acaso, ou, como diria Piaget (1977, p. 9-11), graças à ação inteligente do ser humano que é capaz de extrair significados de suas vivências, qualquer que seja ela e independente da qualidade da medição do outro, o mesmo é capaz de reconstruir para si o conhecimento disponível no seu entorno, porque os professores desconhecem as características básicas do objeto com o qual trabalham - a linguagem. Portanto, os que aprendem, aprendem apesar do professor;

- as professoras desconhecem as necessidades de seus alunos, pois os que encontram maiores dificuldades para reconstruírem o sistema da língua escrita, para então se apropriarem desses conhecimentos, vão sendo excluídos da escola e da sociedade; 
- as professoras acreditam que dar voz aos alunos para conhecer suas necessidades e experiências é perder tempo, com tanto conteúdo curricular a ser trabalhado, e privilegiam as atividades mecânicas e sem sentido - a cópia - para as situações de escrita;

- as professoras não conseguem integrar os conteúdos estudados na universidade com as situações de prática de ensino, e quando o fazem, é para transformar as classes de EJA em cópias farsistas das salas da universidade - como demonstrou o uso do retroprojetor, em uma atividade mal preparada, inadequada até para ser utilizada no ensino superior;

- que a formação das professoras para trabalhar com a alfabetização é insuficiente. Embora algumas delas tivessem boa vontade e fossem carinhosas para tratar com os alunos, é preciso ter em mente o que afirma Guiomar Namo de Mello: para ensinar é preciso ir além do compromisso político, é preciso ter a competência técnica para o fazer.

Ou, como melhor expõe Paulo Freire (1996, p. 23-101) na sua Pedagogia da autonomia, entre tantas outras habilidades lá trabalhadas destacamos a de que ensinar exige segurança, competência profissional e generosidade.

\section{Alguns rudimentos da alfabetização}

Dentre os inúmeros conteúdos que deveriam ser do domínio dos professores alfabetizadores, chamamos a atenção para:

O conhecimento de que o código da língua escrita está para a linguagem assim como o esqueleto está para o corpo humano. É ele que sustenta e dá forma ao corpo, porém é invisível. Da mesma forma, quem lê ou escreve trabalha de forma direta com a linguagem e de forma indireta e inconsciente com o código. Ao pensar em escrever "estou com fome", quem sabe ler e escrever não pensa nas letras que está utilizando, porque as palavras surgem em bloco na mente. Porém, enquanto não se sabe escrever é preciso focar a atenção em cada letra, sem perder o significado do que se quer grafar, porque, como nos informa Morais, ao abordar as difi- 
culdades da aprendizagem da leitura: “(...) a partir do momento em que há demasiada informação a tratar (mais de uma palavra para ler, ou então mais de uma letra para identificar quando a letra se encontra numa palavra), o leitor já não consegue focalizar a sua atenção eficazmente" (MORAIS, 1997, p. 125).

Quer o autor com isso dizer que embora a palavra apareça em bloco na mente do indivíduo, enquanto ele ainda não domina o código precisa prestar atenção em pequenas unidades para conseguir avançar seu conhecimento, senão ele força demasiado a memória e não consegue aprender.

- O conhecimento de que o código da língua escrita não é transparente, como pensam as professoras alfabetizadoras, porque a consciência fonológica é decorrente da alfabetização, já que ela inexiste em sujeitos analfabetos. É a aprendizagem da leitura e da escrita que desenvolve a consciência fonológica - a capacidade de refletir sobre os elementos lingüísticos e estabelecer a relação letra/som que garante o avanço no domínio daquelas habilidades. Conseqüentemente, se o código não é transparente, ele precisa ser ensinado. Porém, para ser aprendido é necessário oferecer oportunidades do aprendiz se colocar de forma ativa diante da tarefa de aprender a ler, conforme afirma Morais: "É importante falar às crianças, fazê-las falar, colocá-las em situação de procura de conhecimentos, de tratamento de informação, de resolução de problemas, de avaliação crítica de ações e julgamentos, e sobretudo de lhes ler, ler, ler" (MORAIS, 1997, p. 258).

É interagindo com a leitura e escrita em situação ativa e real, e com os demais usuários da leitura e escrita, que as crianças, jovens e adultos aprendem a ler e escrever.

Em outra passagem de seu livro, Morais é contundente ao afirmar que aprender a ler envolve processos específicos e complexos e que a sua aprendizagem passa pela descoberta e pela utilização do princípio alfabético de correspondência entre letras e fonemas, e que:

(...) a criança não descobre o princípio alfabético da escrita sem uma instrução explícita de análise fonêmica e das correspondências grafema/ fonema. (...) da mesma forma que não se começa a aprendizagem de piano pedindo ao aluno para interpretar as obras. A relação entre as teclas e as notas têm de ser explicitamente ensinadas no princípio da aprendizagem" (MORAIS, J., 1997, p. 249). 
E conclui dizendo: “(...) é evidente que a criança aprende mais facilmente a ler se se beneficiar de um meio altamente letrado, se os pais gostarem de ler; se lhe lerem histórias em voz alta e se lhe inspirarem o desejo da leitura" (MORAIS, 1997, p. 245).

Comparando essas sugestões com as práticas descritas anteriormente que ocorrem nas salas de aula, verificamos que estamos muito longe de proporcionar situações que ajudem nossas crianças e nossos jovens e adultos a aprenderem a ler e escrever.

E aí surge a indagação: como ensinar sem conhecer o objeto que se quer ensinar? Logo, a resposta possível é que o professor precisa aprender para poder ensinar.

Sobre o como ensinar, Emília Ferreiro (1985, p. 192-224) nos dá algumas pistas, ao revelar que as crianças e também os jovens e adultos reconstroem o sistema da língua escrita para poder se apropriar dele. Deixa claro que no caminho da construção a descoberta da relação letra/som ocorre quando os sujeitos atingem a compreensão silábica do sistema, e nesse momento muitas outras aquisições já foram feitas, como: a distinção entre desenho e escrita e as hipóteses quantitativa, qualitativa e do realismo nominal. Portanto, a descoberta do princípio alfabético não se dá no início do processo de reconstrução do sistema da escrita pelo aprendiz.

\section{Concluindo}

É importante reconhecer que todos esses referenciais teóricos oriundos das diversas ciências que tratam das questões diretamente ligadas à alfabetização - a Psicologia da Educação, a Lingüística, a Lingüística Aplicada, a Psicolingüística, a Sociolingüística e a Pedagogia - ainda não ajudaram a mudar o ensino nas classes de alfabetização. Sequer o fizeram nas universidades, onde se divulgam as teorias já não tão novas. Continuam em suas práticas, despejando conteúdos descontextualizados e cobrando dos alunos a pura e simples devolução. Prova disso é a quantidade de cópias de textos que os alunos têm que dar conta durante o ano letivo. É impossível que os professores consigam trabalhar exaustivamente com tantos textos ao mesmo tempo. 
O Curso de Pedagogia não é ainda um curso voltado para a formação de professores porque não se sensibilizou para a importância de assumir a formação dos professores alfabetizadores da Educação Infantil, das séries iniciais do Ensino Fundamental e da EJA e tampouco os das outras áreas de conteúdo de forma eficiente. Não se sente minimamente responsável pelo pífio resultado obtido pelos alunos brasileiros nos testes nacionais - SAEB e PROVABRASIL - e internacionais - PISA - que avaliaram a competência para ler e compreender textos. Como também não assumiu sua parte de responsabilidade pela baixa qualidade da educação ofertada às crianças, o que faz com que muitas delas sejam excluídas das classes regulares para voltarem posteriormente, com baixa auto-estima, nas salas da EJA, já solapadas em seus direitos humanos e de cidadania.

\section{REFERÊNCIAS}

BRANCO,V.; HARACEMIV, S. M. C e outros. As práticas do alfabetizador na Educação Infantil, séries iniciais do Ensino Fundamental e EJA: aproximações e distanciamentos frente os pressupostos metodológicos do projeto político-pedagógico da escola. Relatório de Pesquisa, Projeto LICENCIAR, UFPR, 2004.

FERREIRO, E.; TEBEROSKY, A. Psicogênese da língua escrita. Porto Alegre: Artes Médicas, 1985.

FREIRE, P. Pedagogia da autonomia. São Paulo: Paz e Terra, 1996.

GUIMARÃES ROSA, J. Grande Sertão: veredas. Rio de Janeiro: Nova Fronteira, 1996.

LYONS, J. Linguagem e lingüística. Rio de Janeiro: Livros Técnicos e Científicos Editora, 1997.

MORAIS, J. A arte de ler: psicologia cognitiva da leitura. Lisboa: Edições Cosmos,1997.

PIAGET, J. A tomada de consciência. São Paulo: Melhoramentos, Editora da Universidade de São Paulo, 1977.

Texto recebido em 17 de nov. 2006

Texto aprovado em 10 de fev. 2007 
Demanda contínua 